Research Article

\title{
Electrochemical Solvent Cointercalation into Graphite in Propylene Carbonate-Based Electrolytes: A Chronopotentiometric Characterization
}

\author{
Hee-Youb Song and Soon-Ki Jeong \\ Department of Chemical Engineering, Soonchunhyang University, Asan, Chungnam 336-745, Republic of Korea \\ Correspondence should be addressed to Soon-Ki Jeong; hamin611@sch.ac.kr
}

Received 30 August 2017; Revised 10 November 2017; Accepted 28 January 2018; Published 6 March 2018

Academic Editor: Larisa Lvova

Copyright @ 2018 Hee-Youb Song and Soon-Ki Jeong. This is an open access article distributed under the Creative Commons Attribution License, which permits unrestricted use, distribution, and reproduction in any medium, provided the original work is properly cited.

\begin{abstract}
Interfacial reactions strongly influence the performance of lithium-ion batteries, with the main interfacial reaction between graphite and propylene carbonate- (PC-) based electrolytes corresponding to solvent cointercalation. Herein, the redox reactions of solvated lithium ions occurring at the graphite interface in $1 \mathrm{M} \cdot \mathrm{LiClO}_{4} / \mathrm{PC}$ were probed by chronopotentiometry, in situ atomic force microscopy (AFM), and in situ Raman spectroscopy. The obtained results revealed that high coulombic efficiency (97.5\%) can be achieved at high current density, additionally showing the strong influence of charge capacity on the above redox reactions. Moreover, AFM imaging indicated the occurrence of solvent cointercalation during the first reduction, as reflected by the presence of hills and blisters on the basal plane of highly oriented pyrolytic graphite subjected to the above process.
\end{abstract}

\section{Introduction}

Graphite is extensively used for the fabrication of lithiumion batteries (LIBs) [1-4] due to being capable of electrochemically intercalating lithium ions into graphene layers and thus enabling electrical energy storage during charging. However, the above intercalation reaction is strongly affected by the nature of the utilized electrolytes, which comprise lithium ions, counter anions, and organic solvents [5]. In electrolyte solutions, the interaction between lithium ions and organic solvents leads to the solvation of the former [6-8], which is undesired and should be inhibited due to solvated lithium ions being intercalated into graphite at more positive potentials than nonsolvated ones [9-12]. In addition, the continuous cointercalation of coordinated solvent leads to graphite exfoliation.

Despite its remarkable ionic conductivity at low temperature (melting point $=-49^{\circ} \mathrm{C}$ ), propylene carbonate $(\mathrm{PC})$, widely used as a main organic solvent in primary lithium batteries, has not been applied to LIBs due to undergoing ceaseless cointercalation into graphite during the first charging [13-16]. PC cointercalation is well known to occur at $\sim 1 \mathrm{~V}$ versus $\mathrm{Li}^{+} / \mathrm{Li}$, hindering the lowering of the electrode potential to values corresponding to lithium intercalation $\left(0.25-0.0 \mathrm{~V}\right.$ versus $\left.\mathrm{Li}^{+} / \mathrm{Li}\right)$ and thus inducing graphite exfoliation prior to lithium intercalation during the first charging. Thus, solvent cointercalation significantly degrades the performance of LIBs and should be suppressed to allow reversible intercalation/deintercalation of lithium ions at graphite-negative electrodes.

The effective suppression of solvent cointercalation at graphite-negative electrode requires a deep understanding of numerous factors of influence. Commonly, the irreversible reduction of solvated lithium ions at $\sim 1 \mathrm{~V}$ is the main interfacial reaction in PC-based electrolyte solutions, indicating the importance of understanding the redox behavior of PC-solvated lithium ions. Herein, we probed the above behavior by chronopotentiometry, characterizing the potential change upon application of negative/positive currents and investigated the effects of current density on the redox reactions of solvated lithium ions. Moreover, in situ atomic force microscopy (AFM) and in situ Raman spectroscopy 


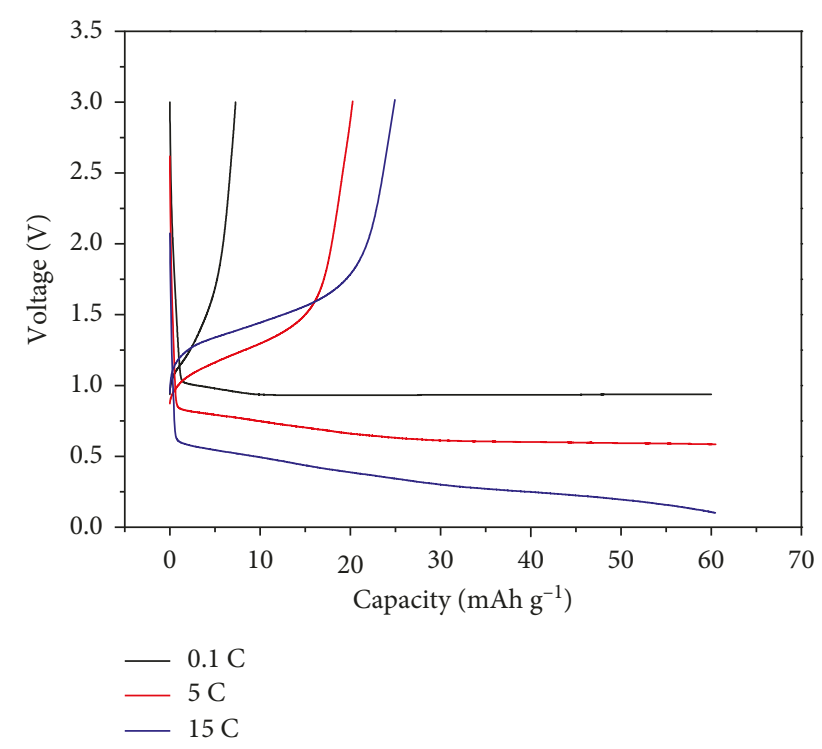

FIgURE 1: Voltage profiles of NG-7 at various C-rates in $1 \mathrm{M} \cdot \mathrm{LiClO}_{4} / \mathrm{PC}$, with the cell charged to $60 \mathrm{mAh} \cdot \mathrm{g}^{-1}$ at each cycle.

were used to clarify certain aspects of solvent cointercalation during the first reduction reaction.

\section{Materials and Methods}

2.1. Preparation of Electrode Materials and Electrolyte Solution. Natural graphite powder (NG-7, Kansai Coke, and Chemicals Co.) was used as an active electrode material for chronopotentiometry. A composite working electrode was prepared by coating copper foil (Nilaco Co.) with a $9: 1$ (w/w) mixture of NG-7 and poly(vinylidene difluoride) and drying it at $80^{\circ} \mathrm{C}$ in a vacuum oven (Yamato Scientific Co., DNE401) for $12 \mathrm{~h}$. Highly oriented pyrolytic graphite (HOPG; Advanced Ceramics, ZYH grade, mosaic spread $=3.5 \pm 1.5^{\circ}$ ) was used as a model electrode for in situ AFM imaging, which was carried out for freshly cleaved HOPG surfaces. Lithium foil (Honjo Metal Co.) was used as reference and counter electrodes in all electrochemical measurements, and a $1 \mathrm{M}$ solution of $\mathrm{LiClO}_{4}$ in PC (Kishida Chemical Co., battery grade) was used as an electrolyte.

2.2. Chronopotentiometry. Chronopotentiometric measurements were performed using a battery test system (Hokuto Denko, HJ101SM6), with 2032 coin cells tested at various C-rates $\left(1 \mathrm{C}=372 \mathrm{~mA} \cdot \mathrm{g}^{-1}\right)$ to understand the effect of current density on the redox behavior of solvated lithium ions.

2.3. In Situ AFM. The basal plane of HOPG was imaged in contact mode using a pyramidal silicon nitride tip (OLYMPUS Co., OMCL-TR800PSA) in $1 \mathrm{M} \cdot \mathrm{LiClO}_{4} / \mathrm{PC}$. AFM images $(5 \mu \mathrm{m} \times 5 \mu \mathrm{m})$ were automatically captured at each potential during cyclic voltammetry (CV) scans between 3.0 and $0.0 \mathrm{~V}$ (scan rate $=2 \mathrm{mV} \cdot \mathrm{s}^{-1}$ ) using an AFM imaging system (Molecular Imaging, PicoSPM ${ }^{\oplus}$ ) equipped with a potentiostat (Molecular Imaging, PicoStat). All AFM characterizations

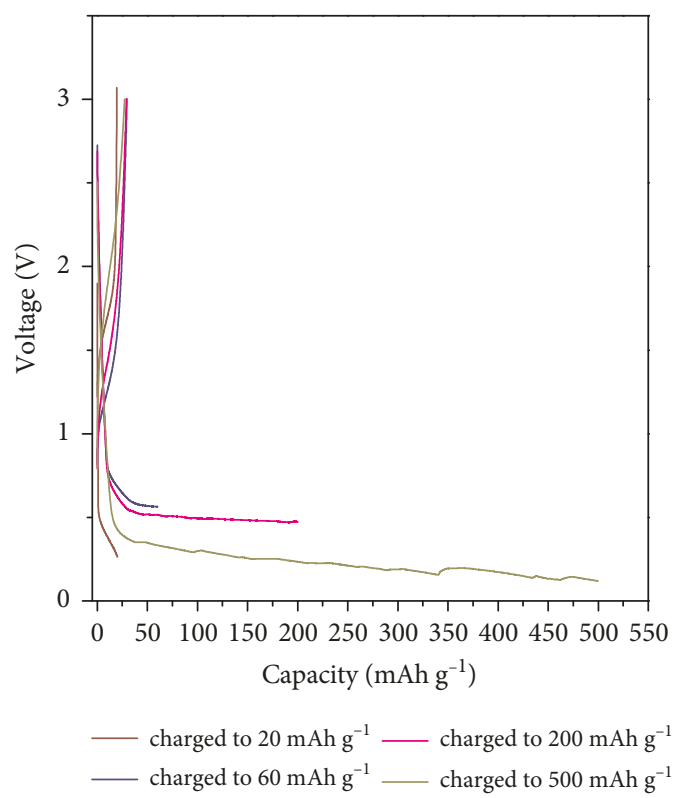

FIGURE 2: Voltage profiles of NG-7 at various charge capacities and a C-rate of $5 \mathrm{C}$ in $1 \mathrm{M} \cdot \mathrm{LiClO}_{4} / \mathrm{PC}$.

were performed at room temperature in an argon-filled glove box (Miwa, MDB-1B + MM3-P60S, dew point $<-70^{\circ} \mathrm{C}$ ).

2.4. In Situ Raman Spectroscopy. An electrochemical (quartz) cell for in situ Raman spectroscopy was assembled in an argon-filled glove box, sealed, and removed from the glove box into ambient atmosphere. The $514.5 \mathrm{~nm}$ line of an argon-ion laser was scattered on HOPG during the first reduction by applying a constant current of $1 \mathrm{C}$. Raman spectra were collected using a triple monochromator (Jobin-Yvon, T64000) equipped with a multichannel charge-coupled device detector.

\section{Results and Discussion}

3.1. Effect of Current Density on Solvent Cointercalation. Figure 1 shows voltage profiles recorded at various $\mathrm{C}$-rates in $1 \mathrm{M} \cdot \mathrm{LiClO}_{4} / \mathrm{PC}$. During these measurements, the graphitenegative electrode was charged to $60 \mathrm{mAh} \cdot \mathrm{g}^{-1}$ and instantly discharged without any rest time, providing insights into the redox behavior of solvated lithium ions above the lithium intercalation potential, with a different discharge capacity observed in each cycle reflecting the oxidation of solvated lithium ions. In general, solvent cointercalation (corresponding to the reduction of solvated lithium ions) takes place at $\sim 1 \mathrm{~V}$ in PC-based electrolytes [13-16]. However, in this case, the solvent cointercalation potential decreased, and the discharge capacity increased as the current density increased from 0.1 to 5 or $15 \mathrm{C}$, indicating the occurrence of reversible redox reactions of solvated lithium ions at graphite and additionally showing that the oxidation of solvated lithium ions can be controlled by choosing an appropriate current density.

For further experiments, we selected a C-rate of $5 \mathrm{C}$ and investigated the discharge capacity of fabricated cells to 


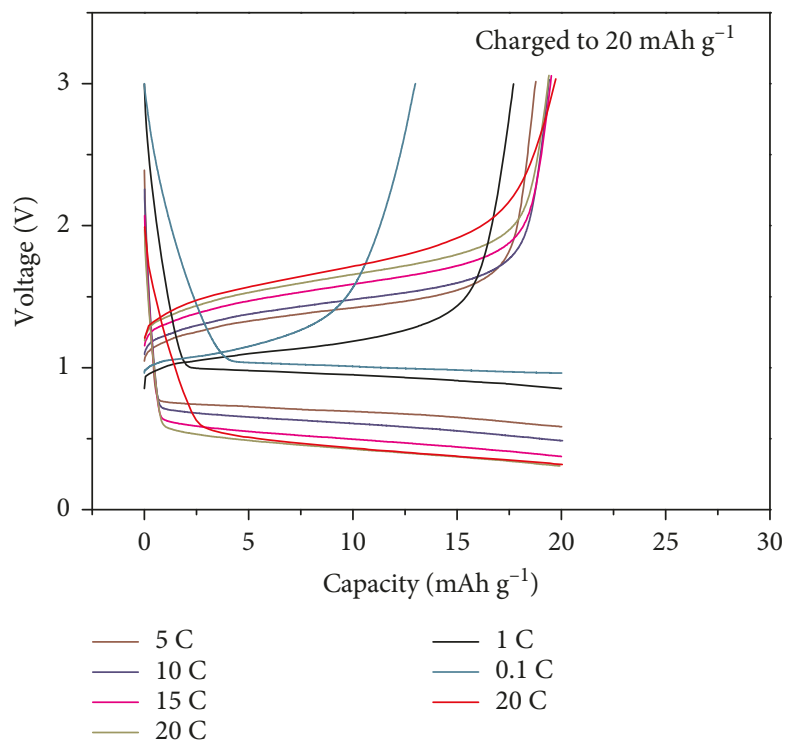

(a)

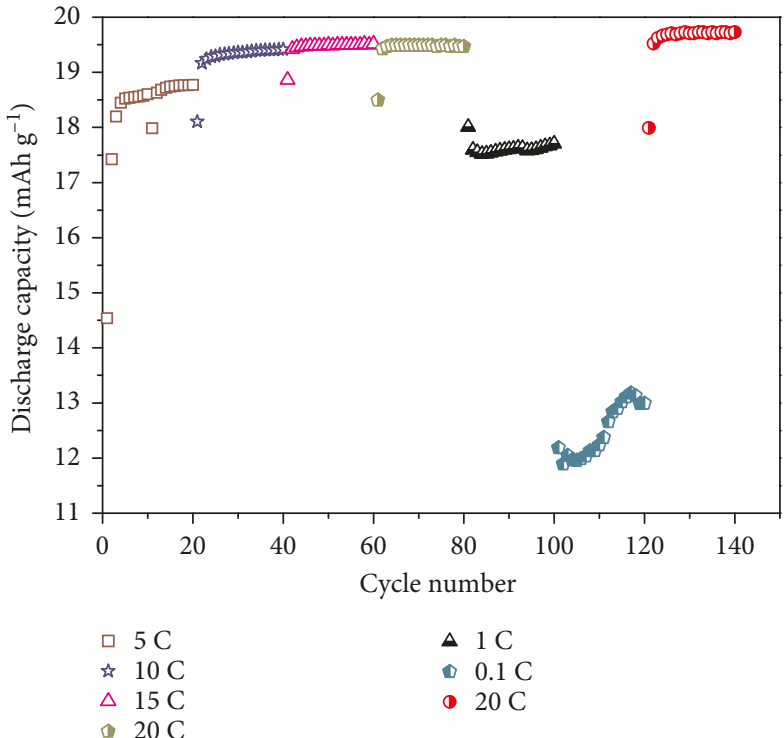

(b)

Figure 3: (a) Voltage profiles and (b) cycling performance of NG-7 at various C-rates in $1 \mathrm{M} \cdot \mathrm{LiClO}_{4} / \mathrm{PC}$, with the cell charged to $20 \mathrm{mAh} \cdot \mathrm{g}^{-1}$.

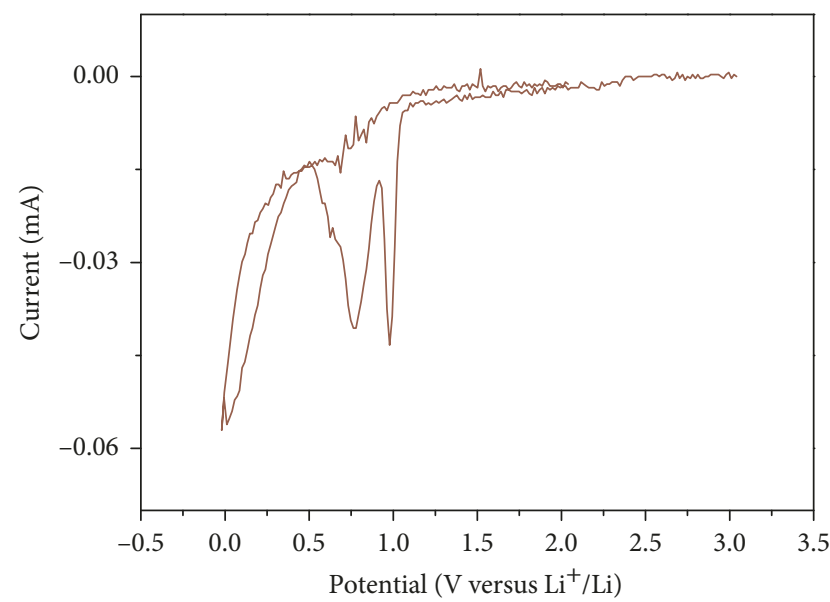

FIgUre 4: Cyclic voltammogram of HOPG during the first cycle in $1 \mathrm{M} \cdot \mathrm{LiClO}_{4} / \mathrm{PC}$ recorded at a scan rate of $2 \mathrm{mV} \cdot \mathrm{s}^{-1}$.

understand the effect of charge capacity on the redox reactions of solvated lithium ions. Notably, no significant increase of discharge capacity $\left(\sim 20 \mathrm{mAh} \cdot \mathrm{g}^{-1}\right)$ was observed as the charge capacity increased from 20 to $500 \mathrm{mAh} \cdot \mathrm{g}^{-1}$ (Figure 2). Moreover, coulombic efficiency increased with decreasing charge capacity, indicating that the redox reactions of solvated lithium ions could be controlled by varying both current density and charge capacity.

Figure 3(a) shows charge and discharge capacities obtained for a cell charged to $20 \mathrm{mAh} \cdot \mathrm{g}^{-1}$ above the lithium intercalation potential at various current densities. The corresponding coulombic efficiency was estimated as $65 \%$ at $0.1 \mathrm{C}$, increasing to $\geq 97.5 \%$ at 10,15 , and $20 \mathrm{C}$ and thus indicating that most solvated lithium ions cointercalated into graphite were oxidized at the above high current densities during discharge. Furthermore, the discharge capacity was sustained after 140 cycles (Figure 3(b)). Thus, the redox reactions of solvated lithium ions at graphite in PC-based electrolytes were demonstrated to be dependent on current density and charge capacity.

\subsection{In Situ AFM and Raman Investigation of HOPG during} the First Reduction. Morphological changes of the HOPG basal plane were investigated by in situ AFM to obtain further insights into solvent cointercalation in PC-based electrolytes. Figure 4 shows a cyclic voltammogram of HOPG in $1 \mathrm{M} \cdot \mathrm{LiClO}_{4} / \mathrm{PC}$, revealing the presence of three reduction peaks at potentials below $1.0 \mathrm{~V}$ during the first cycle. Prior to reduction, HOPG exhibited a flat surface comprising basal and edge planes (Figure 5(a)), with significant morphological changes observed after reduction; that is, hill-like structures were detected on the HOPG basal plane at $\sim 1 \mathrm{~V}$ (Figure 5(b)). Similarly, Inaba et al. observed related structures on the surface of graphite after cointercalation of solvated lithium ions, ascribing the formation of blisters to the decomposition of solvated lithium ions within graphite $[11,13]$. Accordingly, the reduction peak at $\sim 1 \mathrm{~V}$ was attributed to solvent cointercalation into graphite, with blistering at decreased cell potentials (Figure 5(c)) explained as mentioned above. In addition, the height of the HOPG basal plane increased in a potential range of $0.49-0.0 \mathrm{~V}$ (Figure $5(\mathrm{~d})$ ).

We also employed in situ Raman spectroscopy to clarify the nature of the intercalate formed during the first reduction of graphite in constant-current mode in a PC-based electrolyte. In this case, the electrode potential did not drop to the lithium intercalation potential while the graphite electrode was charged to $20 \mathrm{mAh} \cdot \mathrm{g}^{-1}$ in the same manner as shown in Figure 3(a). However, both $\mathrm{E}_{2 \mathrm{~g} 2}$ (interior) and $\mathrm{E}_{2 \mathrm{~g} 2}$ (boundary) bands at 1583 and $1597 \mathrm{~cm}^{-1}$, respectively, 


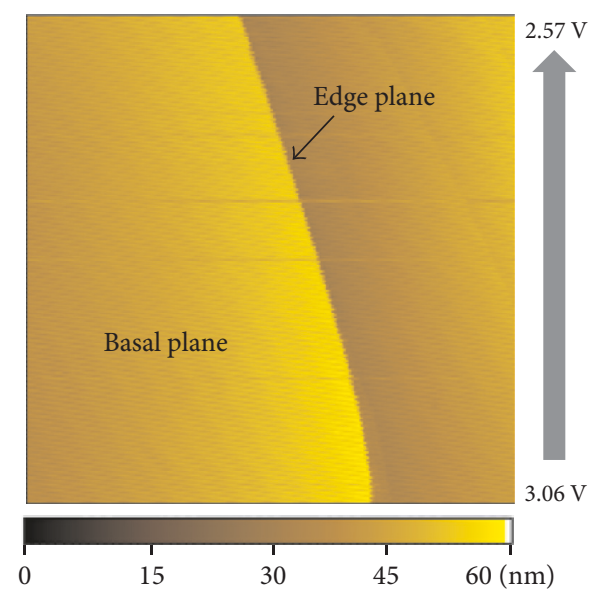

(a)

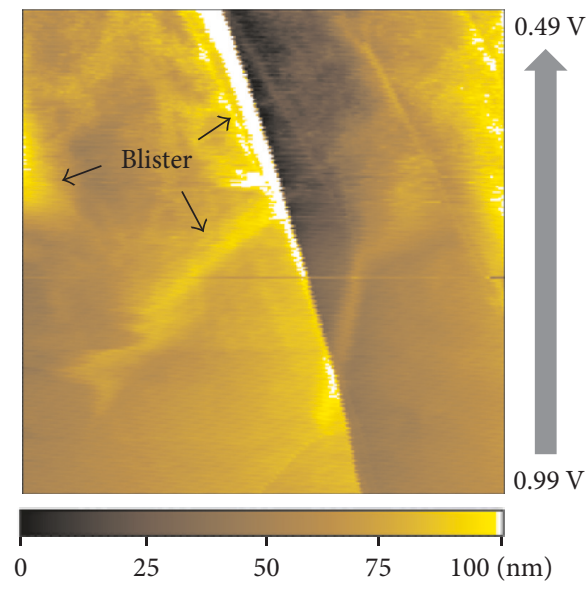

(c)

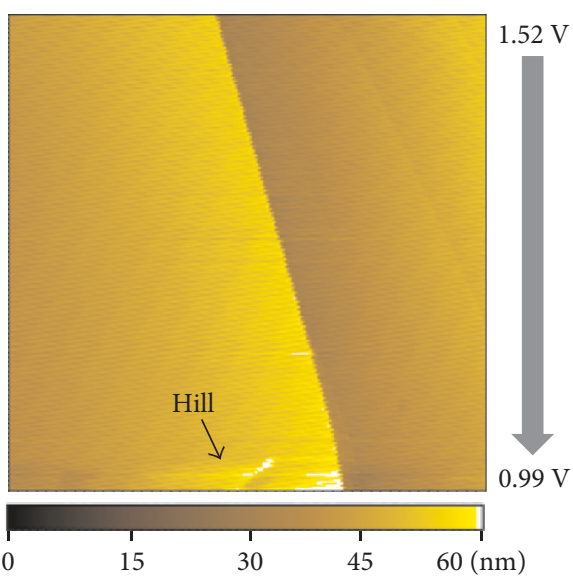

(b)

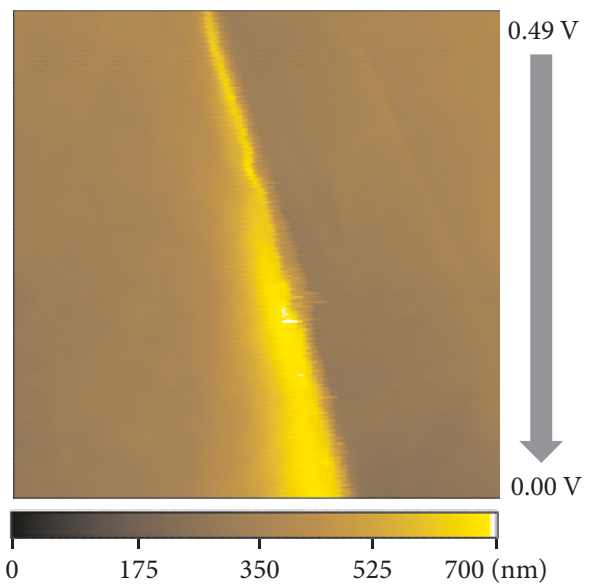

(d)

Figure 5: In situ AFM images of the HOPG basal plane $(5 \mu \mathrm{m} \times 5 \mu \mathrm{m})$ obtained at (a) $3.06-2.57$, (b) $1.52-0.99$, (c) $0.99-0.49$, and (d) $0.49-0.0 \mathrm{~V}$ during the first reduction in $1 \mathrm{M} \cdot \mathrm{LiClO}_{4} / \mathrm{PC}$.

were observed during the first reduction reaction, indicating the absence and presence of intercalates within graphite layers, respectively (Figure 6). Moreover, the first reduction increased the intensity of the latter band and decreased that of the former, indicating that continuous cointercalation of PC-solvated lithium ions into graphite occurred at a potential higher than that of lithium intercalation. Based on the insights provided by in situ AFM and in situ Raman analysis, the results of chronopotentiometric characterization were attributed to the redox reactions of solvated lithium ions in the PC-based electrolyte.

\section{Conclusions}

Herein, we investigated the redox reactions of solvated lithium ions at graphite in $1 \mathrm{M} \cdot \mathrm{LiClO}_{4} / \mathrm{PC}$ by chronopotentiometry, in situ AFM, and in situ Raman spectroscopy, revealing that these reactions were reversible at high current density and thus highlighting the key role of the latter parameter. Moreover, the discharge capacity related to the oxidation of solvated lithium ions increased with increasing current density, and improved coulombic efficiency was observed at high current densities of 10,15, and $20 \mathrm{C}$ in the case of charging to $20 \mathrm{mAh} \cdot \mathrm{g}^{-1}$. AFM imaging revealed the appearance of hills and blisters on the otherwise smooth electrode surface during the first reduction, indicating the occurrence of solvent cointercalation and decomposition at graphite. Thus, the redox reactions of solvated lithium ions were shown to be the main interfacial reactions taking place at the graphite-negative electrode, with their control being possible by appropriate variation of current density and charge capacity.

\section{Conflicts of Interest}

The authors declare that they have no conflicts of interest.

\section{Acknowledgments}

This research was supported by the Basic Science Research Program through the National Research Foundation of Korea (NRF) funded by the Ministry of Education (No. NRF-2017R1A2B4010544). This work was supported by the Soonchunhyang University Research Fund. 


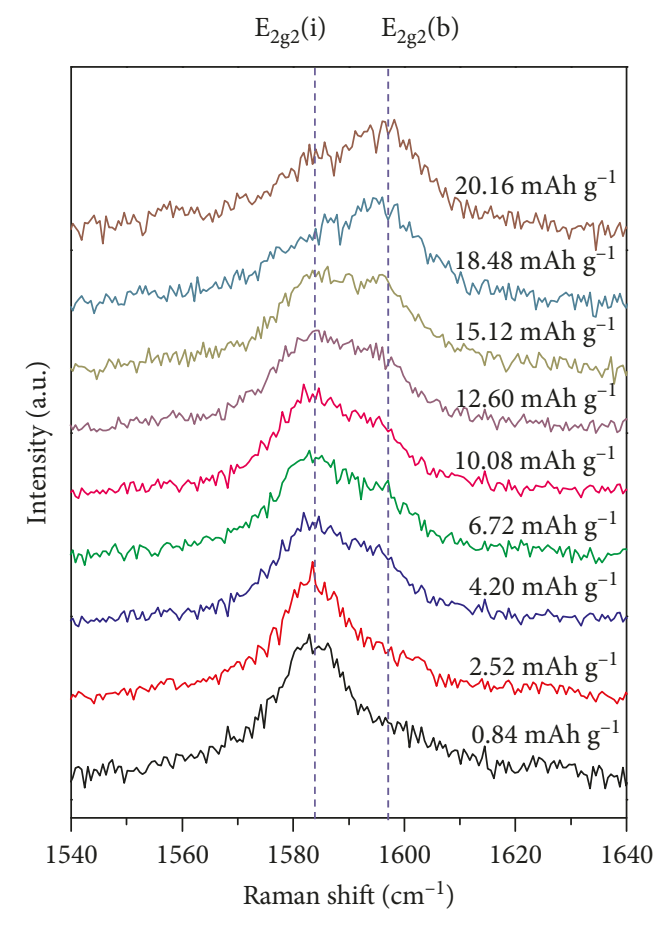

FIgURE 6: In situ Raman spectra of HOPG recorded during the first reduction in constant-current mode $(1 \mathrm{C})$ in $1 \mathrm{M} \cdot \mathrm{LiClO}_{4} / \mathrm{PC}$. The electrochemical cell was charged to $\sim 20 \mathrm{mAh} \cdot \mathrm{g}^{-1}$.

\section{References}

[1] M. S. Dresselhaus and G. Dresselhaus, "Intercalation compounds of graphite," Advances in Physics, vol. 30, no. 2, pp. 139-326, 1981.

[2] Z. Ogumi and M. Inaba, "Electrochemical lithium intercalation within carbonaceous materials: intercalation processes, surface film formation, and lithium diffusion," Bulletin of the Chemical Society of Japan, vol. 71, no. 3, pp. 521-534, 1998.

[3] M. Inaba, H. Yoshida, Z. Ogumi, T. Abe, Y. Mizutani, and M. Asano, "In situ Raman study on electrochemical Li intercalation into graphite," Journal of the Electrochemical Society, vol. 142, no. 1, pp. 20-26, 1995.

[4] D. Aurbach and Y. Ein-Eli, "The study of Li-graphite intercalation processes in several electrolyte systems using in situ X-ray diffraction," Journal of the Electrochemical Society, vol. 142, no. 6, pp. 1746-1752, 1995.

[5] K. Xu, "Nonaqueous liquid electrolytes for lithium-based rechargeable batteries," Chemical Reviews, vol. 104, no. 10, pp. 4303-4418, 2004.

[6] S.-K. Jeong, M. Inaba, Y. Iriyama, T. Abe, and Z. Ogumi, "Electrochemical intercalation of lithium ion within graphite from propylene carbonate solutions," Electrochemical and Solid-State Letters, vol. 6, no. 1, pp. A13-A15, 2003.

[7] Y. Yamada, Y. Koyama, T. Abe, and Z. Ogumi, "Correlation between charge-discharge behavior of graphite and solvation structure of the lithium ion in propylene carbonatecontaining electrolytes," The Journal of Physical Chemistry C, vol. 13, no. 20, pp. 8948-8953, 2009.

[8] X. Bogle, R. Vazquez, S. Greenbaum, A. W. Cresce, and K. Xu, "Understanding $\mathrm{Li}^{+}$-solvent interaction in nonaqueous carbonate electrolytes with ${ }^{17} \mathrm{O}$ NMR," The Journal of Physical Chemistry Letters, vol. 4, no. 10, pp. 1664-1668, 2013.
[9] J. O. Besenhard, M. Winter, J. Yang, and W. Biberacher, "Filming mechanism of lithium-carbon anodes in organic and inorganic electrolytes," Journal of Power Sources, vol. 54, no. 2, pp. 228-231, 1995.

[10] T. Abe, N. Kawabata, Y. Mizutani, M. Inaba, and Z. Ogumi, "Correlation between cointercalation of solvents and electrochemical intercalation of lithium into graphite in propylene carbonate solution," Journal of The Electrochemical Society, vol. 150, no. 3, pp. A257-A261, 2003.

[11] M. Inaba, Z. Siroma, A. Funabiki, and Z. Ogumi, "Electrochemical scanning tunneling microscopy observation of highly oriented pyrolytic graphite surface reactions in an ethylene carbonate-based electrolyte solution," Langmuir, vol. 12, no. 6, pp. 1535-1540, 1996.

[12] H.-Y. Song, T. Fukutsuka, K. Miyazaki, and T. Abe, "Suppression of co-intercalation reaction of propylene carbonate and lithium ion into graphite negative electrode by addition of diglyme," Journal of the Electrochemical Society, vol. 163, no. 7, pp. A1265-A1269, 2016.

[13] M. Inaba, Z. Siroma, Y. Kawatate, A. Funabiki, and Z. Ogumi, "Electrochemical scanning tunneling microscopy analysis of the surface reactions on graphite basal plane in ethylene carbonate-based solvents and propylene carbonate," Journal of Power Sources, vol. 68, no. 2, pp. 221-226, 1997.

[14] D. Aurbach, B. Markovsky, I. Weissman, E. Levi, and Y. EinEli, "On the correlation between surface chemistry and performance of graphite negative electrodes for li ion batteries," Electrochimica Acta, vol. 45, no. 1-2, pp. 67-86, 1999.

[15] D. Aurbach, M. Koltypin, and H. Teller, "In situ AFM imaging surface phenomena on composite graphite electrodes during lithium insertion," Langmuir, vol. 18, no. 23, pp. 9000-9009, 2002.

[16] K. Xu, "Whether EC and PC differ in interphasial chemistry on graphite anode and how," Journal of The Electrochemical Society, vol. 156, no. 9, pp. A751-A755, 2009. 

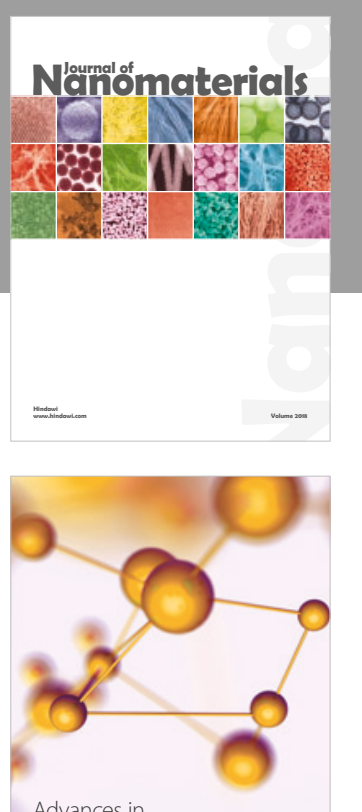

Physical Chemistry
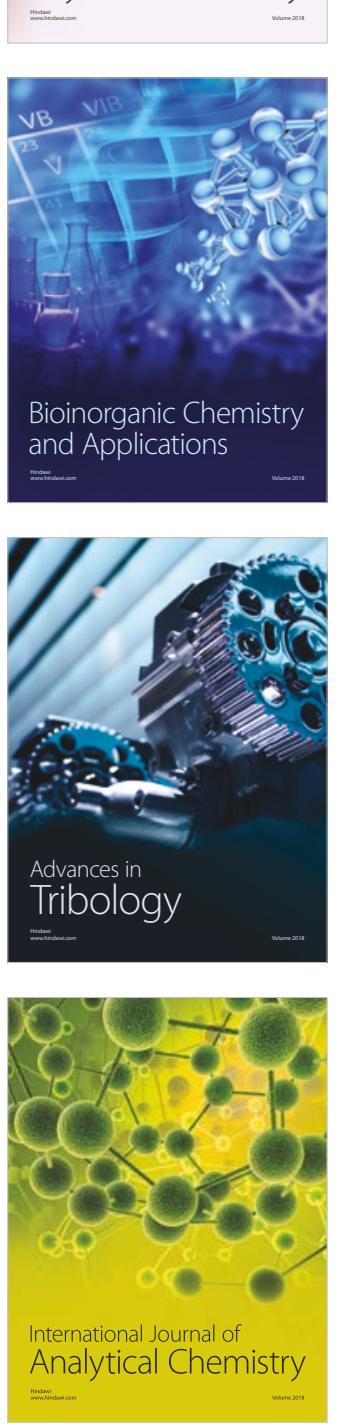

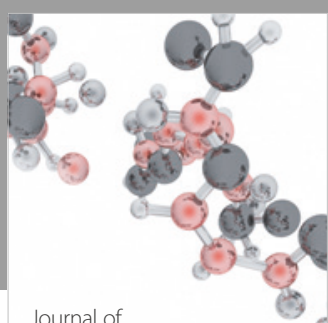

Analytical Methods

in Chemistry

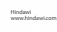

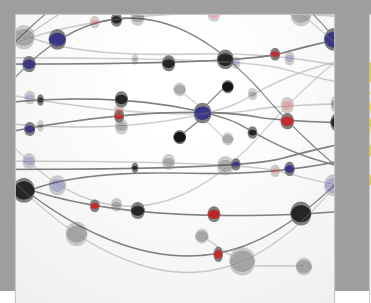

The Scientific World Journal

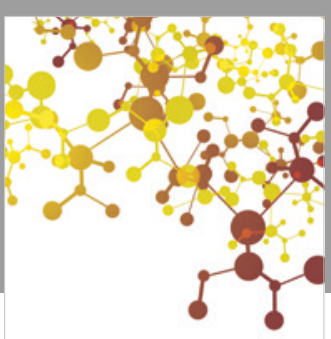

Journal of

Applied Chemistry
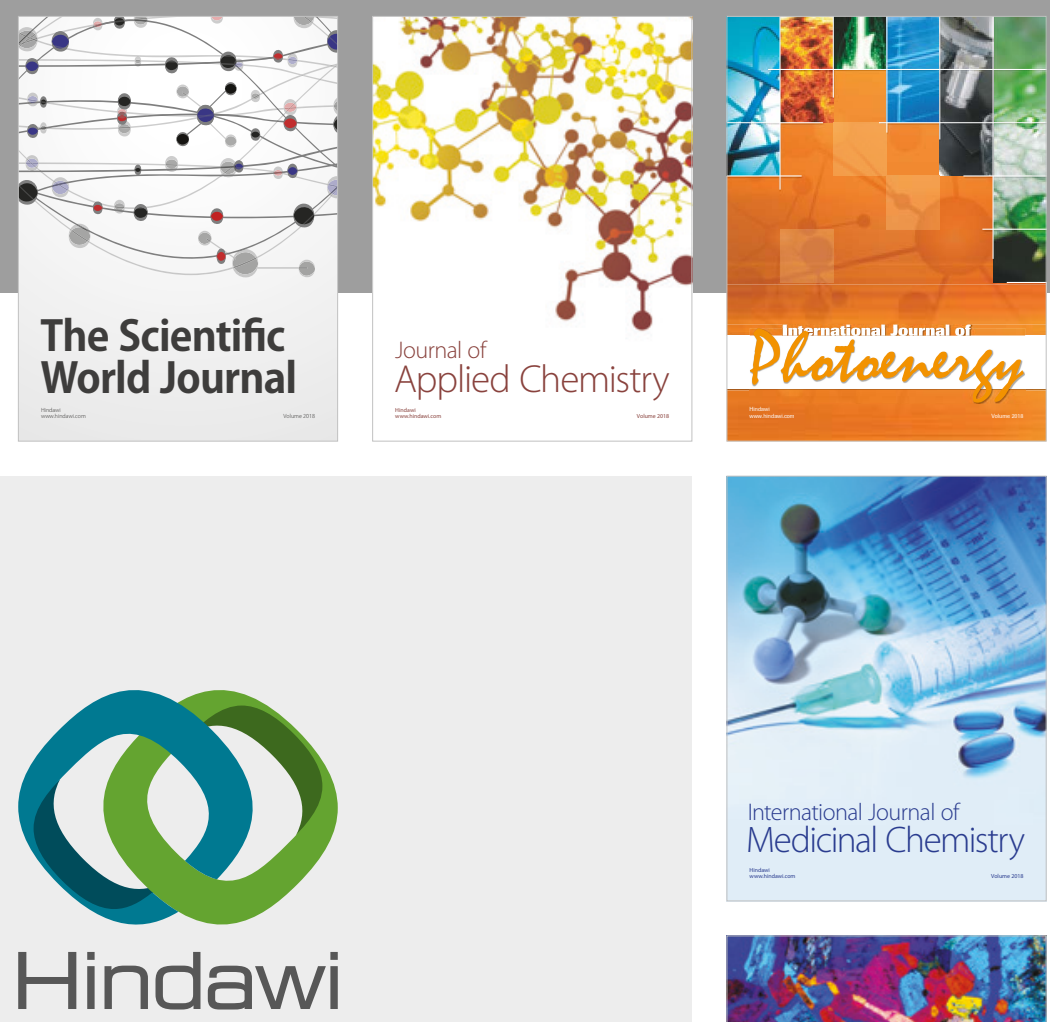

Submit your manuscripts at

www.hindawi.com
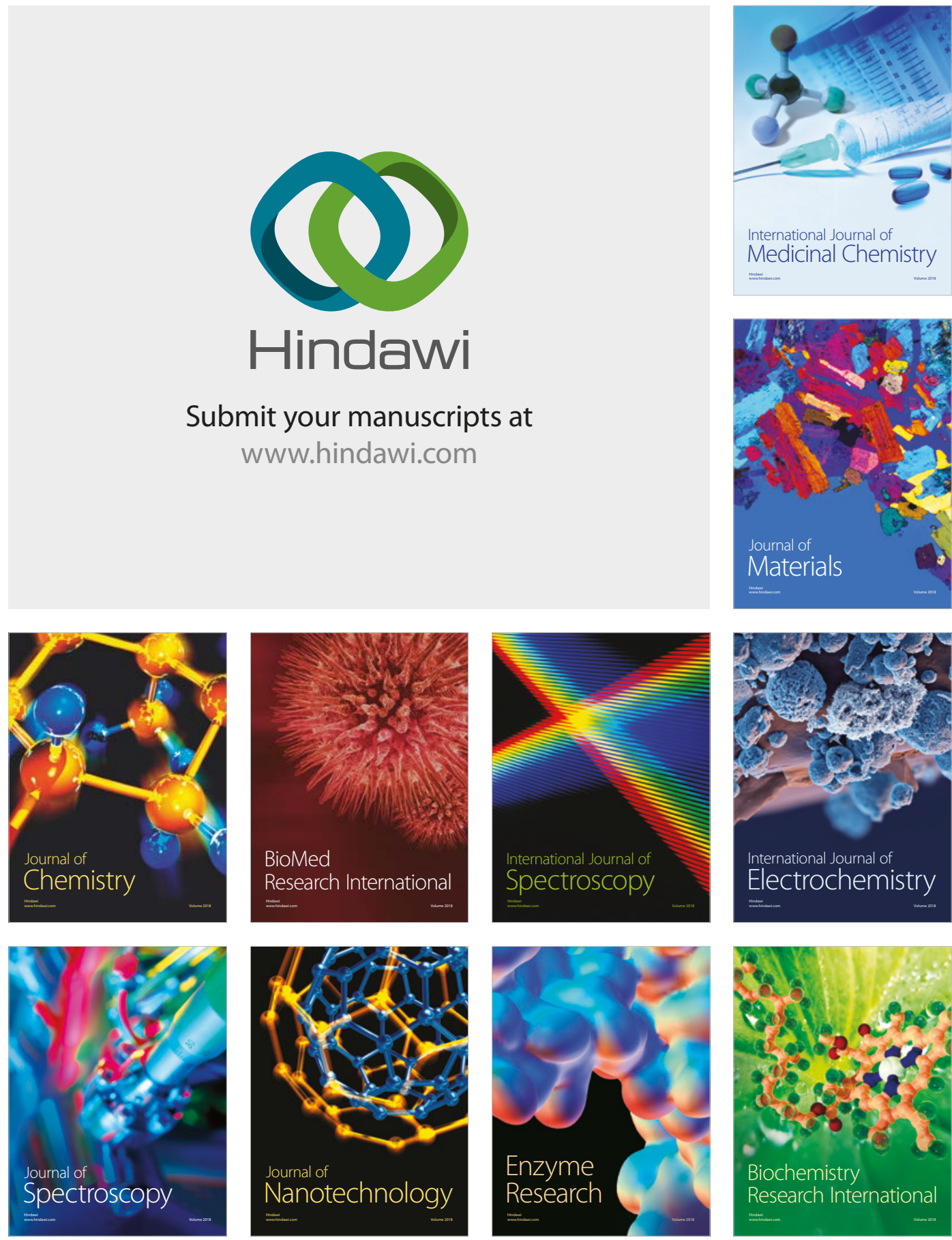
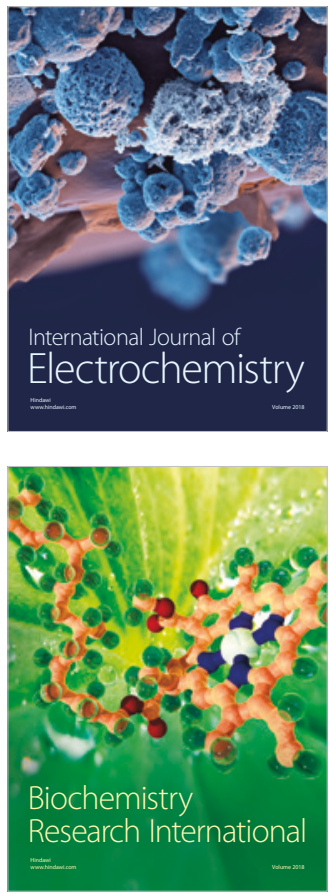